\title{
DEEP LEVEL CONTRIBUTION TO THE CARRIER GENERATION AND RECOMBINATION IN HIGH RESISTIVITY Si IRRADIATED BY NEUTRONS
}

\author{
J. Vaitkus, R. Bondzinskas, V. Kažukauskas, P. Malinovskis, A. Mekys, G. Mockevičius, \\ J. Storasta, N. Vainorius, and E. Žąsinas \\ Institute of Applied Research and Department of Semiconductor Physics, Vilnius University, Sauletekio 9-III, \\ LT-10222 Vilnius, Lithuania \\ E-mail: juozas.vaitkus@ff.vu.lt
}

Received 4 November 2011; revised 23 November 2011; accepted 1 December 2011

\begin{abstract}
Deep level spectroscopy in neutron irradiated $\mathrm{FZ}$ and $\mathrm{MCz} \mathrm{Si}$ was performed by extrinsic photoconductivity spectra measurements in the range of temperature of 18-120 K. The Lukovsky model was used, and the Gaussian distribution of deep level energy demonstrated the best fit of simulation and experimental data. The nonmonotonous change of deep levels during annealing, and non-monotonous dependence of their concentration on the fluence were observed. The photoconductivity decay was investigated by the transient photo-Hall effect, recombination parameters of the main recombination centre were determined, and the recombination centre model was proposed. The photoconductivity and thermally stimulated current measurements were used to demonstrate the existence of photogeneration of free carriers by a cascade of optical and thermal transitions.
\end{abstract}

Keywords: deep levels, radiation defects, $\mathrm{Si}$, photoconductivity, thermally stimulated current PACS: 72.20.Jv, 72.20.My, 72.80.Cw, 71.55.Cn, 29.40.Wk

\section{Introduction}

The Large Hadron Collider (LHC) in CERN needs upgrading to get scientific results in the future nearer than it was planned earlier $[1,2]$. It requires increasing luminosity from $10^{34}$ to $10^{35}$ protons/ $\mathrm{cm}^{2} \mathrm{~s}$, but then it is necessary to increase the radiation hardness of semiconductor detectors to $10^{16}$ hadrons $/ \mathrm{cm}^{2}$. The radiation defects cause a decrease of the charge collection efficiency that is closely related to the non-equilibrium carrier lifetime and generation lifetime in the detector.

Generation lifetime depends on deep levels. Up to now it is concluded that only Si detectors can fulfil specifications for the LHC, including the cost and duration of fabrication of necessary amount of detectors. Therefore, the choice of silicon crystal growth and the detector processing technology are the ways of improving the detector radiation hardness. The control of defects and their role in semiconductors can be investigated by many different methods.

Defect generation by hadron irradiation in silicon, and the change of defect types due to a high vacancy migration rate during sample annealing and reactions between them, with interstitial atoms and impurities are well analysed $[3,4]$. The vacancies are mostly generated inside the clusters, but they are also in the bulk of crystal; therefore, the redistribution and modification of defects inside and outside the cluster change the compensation of the bulk, the parameters of traps and recombination centres. In this work, we analyse deep levels by extrinsic photoresponse spectroscopy and intrinsic photoconductivity kinetics in irradiated and annealed Si detectors.

Different methods used for the investigation of irradiated Si detectors demonstrate the existence of many different traps, and their set is different in the 
samples that are irradiated to the different fluence $[5,6]$, but analysis of the response to the short pulse excitation [7] showed that the photoconductivity decay time constant linearly depends on the fluence in a wide range of fluence $\left(10^{12}-10^{16}\right.$ hadrons/ $\mathrm{cm}^{2}$ ). This result allows predicting the existence of the main recombination channel related to the fluence, and it is possible if the hadron stopping range is bigger than the thickness of the sample.

In this work, the investigation of photoconductivity kinetics was used for the investigation of the main recombination centre and determination of its capture cross-section that may allow proposing the origin of the centre. Also, the spectral dependence of photoresponse was used to characterise deep levels in the samples.

\section{Samples and measurement methods}

A $1 \mathrm{k} \Omega \mathrm{cm} \mathrm{n}-\mathrm{MCz}\langle 100\rangle$ silicon wafer and pad detectors fabricated according to the CERN RD50 collaboration scheme [8] were irradiated with reactor neutrons at the research reactor of the Jozef Stefan Institute in Ljubljana. The fluence was normalised to the equivalent fluence of $1 \mathrm{MeV}$ neutrons. Samples for the Hall effect investigation were fabricated by cutting the wafer into $7 \times 2 \times 0.28 \mathrm{~mm}^{3}$ bars, and Aquadag planar contacts were processed for classical Hall measurements. The contact properties were controlled from the linear current dependence on bias voltage. The measurements were carried out at room temperature (RT). The Hall voltage measurements were performed with a B7-30 multimetre (1 T $\Omega$ input resistance); the current through the sample was measured with a Keithley 6430 multimetre, which was simultaneously used as a voltage source. All measurements were performed in a cryostat in the vacuum of $10^{-2}$ to $10^{-3}$ Torr. A short (15-18 ns) Nd :YAG laser pulse was used for the photo-generation of carriers. In this case the transient photo-Hall technique [9] was applied to evaluate the time dependent non-equilibrium carrier concentration decay. The photo-Hall effect peculiarity analysis in these samples will be published elsewhere.

The time dependence of photoconductivity and Hall effect was measured in separate measurements. The time constant of the measurement system was approximately $15 \mathrm{~ns}$.
The decay of free carrier concentration was analysed by calculating the instantaneous decay time constant [10]:

$$
\frac{1}{\tau}=-\frac{\frac{\mathrm{d} n}{\mathrm{~d} t}}{n},
$$

where $n$ is the experimental value obtained from the photoresponse kinetics and fitting with the instantaneous time constant dependence on the nonequilibrium carrier concentration in the case of nonlinear filling of the recombination centre:

$$
\frac{1}{\tau}=\gamma\left(P_{\mathrm{R} 0}+\Delta n\right),
$$

where $\gamma$ is the carrier capture coefficient, $\gamma=\sigma_{n \mathrm{R}} v_{n T}$, $\sigma_{n \mathrm{R}}$ is the capture cross-section of local level, $v_{n T}$ is electron thermal velocity at temperature $T$.

The photoconductivity spectra were measured in the $\mathrm{p}^{*}-\mathrm{n}-\mathrm{n}^{*}$ samples by using the double prism monochromator DMR-4 and electrometer HP $4140 B$. The light source was calibrated to keep the same number of light quantum at any wavelength used. A sample was placed in a closed cycle $\mathrm{He}$ cryostat (ARS Cryo) and its temperature was measured by the Scientific Instruments 9700 controller. The data were processed by PC with GPIB interface. The main measurements were performed at $50 \mathrm{~V}$ bias. The photoconductivity spectra were analysed using the deep centre model with $\delta$-potential (Lucovsky model [11]):

$$
I \sim m \cdot \Delta E_{\mathrm{M}}^{0.5}\left(h v-\Delta E_{\mathrm{M}}\right)^{1.5} /(h v)^{3} .
$$

where $\Delta E_{\mathrm{M}}$ is the optical activation energy of the deep centre, $h v$ is the photon energy, $m$ is the concentration of a filled deep centre in the case of electron excitation and the concentration of an empty deep centre in the case of hole excitation. The experimental data were fitted to a set of deep levels providing that their energies can be randomly different, and the fitting parameters were the activation energy of the local level and the width of the Gaussian distribution of this energy.

\section{Results}

The measurement of photoconductivity decay in a sample irradiated to the fluence of 


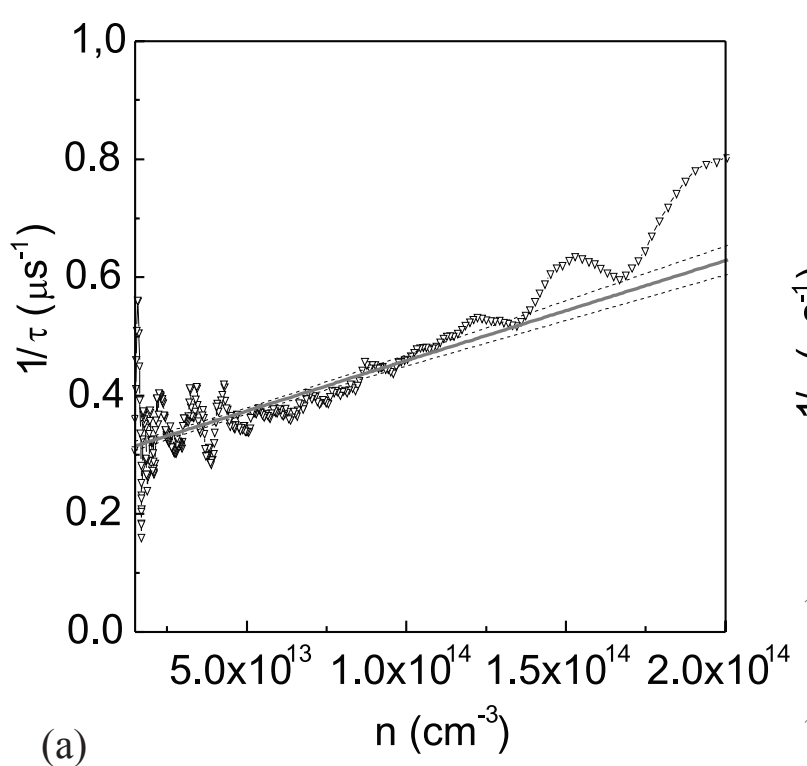

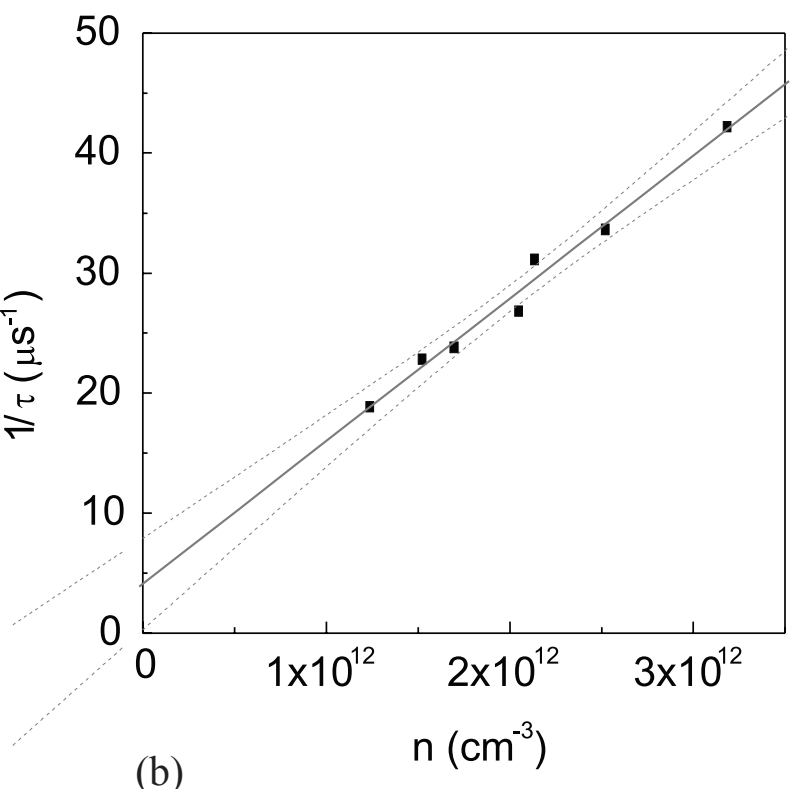

Fig. 1. Dependence of the instantaneous decay constant on non-equilibrium carrier concentration in the irradiated Si samples: (a) fluence $10^{12} \mathrm{~cm}^{-2}$; (b) fluence $10^{14} \mathrm{~cm}^{-2}$. Dots represent experimental data, grey line shows linear fit, dot lines indicate $95 \%$ confidence fit.

$10^{12}$ neutrons $/ \mathrm{cm}^{2}$ (Fig. 1(a)) gave the values of the recombination coefficient $\gamma=2.1 \cdot 10^{-9} \mathrm{~cm}^{3} / \mathrm{s}$, or, in terms of the free carrier capture cross-section, $\sigma_{n \mathrm{R}}=1 \cdot 10^{-16} \mathrm{~cm}^{2}$, which corresponds to the value typical of a neutral capture centre. At the increase of the fluence to $10^{13} \mathrm{n} / \mathrm{cm}^{2}$, the evaluated capture coefficient of the recombination centre was found to be equal to $\gamma=1.9 \cdot 10^{-8} \mathrm{~cm}^{3} / \mathrm{s}\left(\right.$ or $\sigma_{\mathrm{nR}}=8.3 \cdot 10^{-}$ ${ }^{16} \mathrm{~cm}^{2}$ ).

This result still fits the capture cross-section corresponding to the neutral centre type, but a certain process that enhances the capture exists. At the fluence of $10^{14} \mathrm{n} / \mathrm{cm}^{2}$ (Fig. 1(b)) the recombination centre capture coefficient increases 630 times $\left(\gamma=1.2 \cdot 10^{-5} \mathrm{~cm}^{3} / \mathrm{s}\right)$ and the capture cross-section $5.2 \cdot 10^{-13} \mathrm{~cm}^{2}$ corresponds to the attractive centre type. In the samples irradiated to higher fluencies, the time constant became shorter than the light excitation pulse and the photoresponse decreased linearly with the fluence, which demonstrated the increase of recombination centre concentration. These experimental data can be interpreted by the model assuming that the main recombination centres are the clusters. In the initial Si, the cluster is surrounded by the repulsive barrier; therefore, the capture of a non-equilibrium hole makes this centre neutral, as observed experimentally. Other properties can be explained proposing a decrease of the effective bandgap in the cluster, which follows from analysis of multi-vacancy complexes [12]. Then the increase of compensation in the irradiated Si leads to the decrease of the space charge around the cluster and to the change of the cluster into an attractive centre if the Fermi level in the cluster becomes closer to the conduction band than in the bulk of the sample, as observed. It follows that the recombination (capture) of carriers is mainly caused by the clusters in the irradiated $\mathrm{Si}$, and the lifetime depends on the distance between the clusters that is directly related to the fluence. Therefore, the main way of the reduction of the charge collection efficiency in these samples is an increase of bias to achieve the electron extraction time shorter than its migration time to the cluster.

A typical extrinsic photoconductivity spectrum measured in the irradiated $\mathrm{Si}$ is presented in Fig. 2, and the dependence of the fitting parameters on the sample annealing and on the fluence are given in Figs. 3 and 4. These results confirm the data obtained during the preliminary investigation presented in [13], and also theoretical models [4] that a system of many vacancies and different other defect transformations has many 


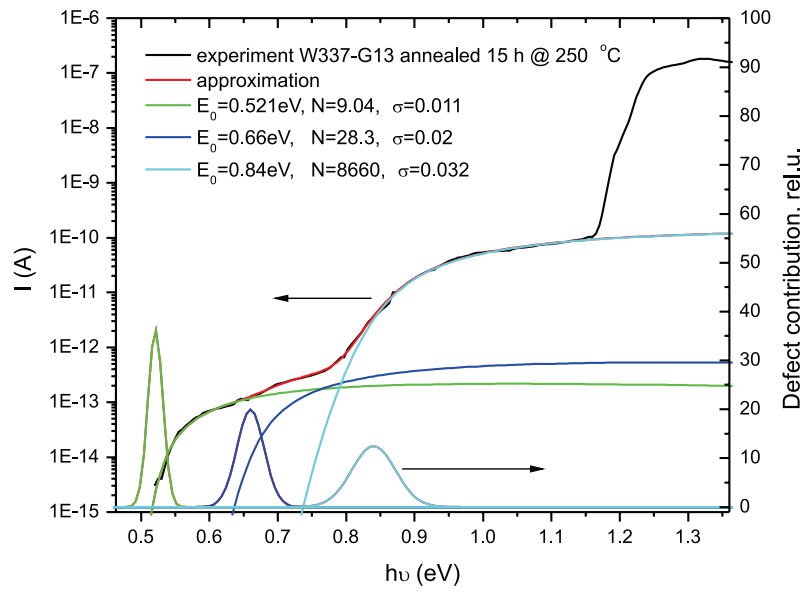

Fig. 2. A typical photoconductivity spectral dependence in the neutron irradiated Si (right axis). Left axis data present the relative contribution of the deep level if its activation energy is approximated by the Gaussian distribution.

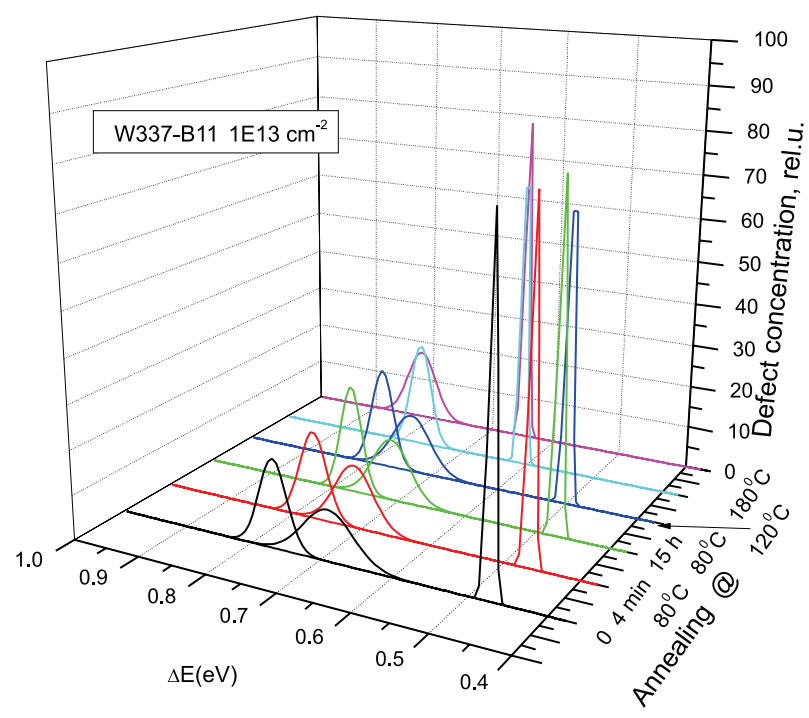

Fig. 3. The dependence of relative contribution of the deep level if its activation energy is approximated by the Gaussian distribution on the sample annealing.

possibilities, and the performed measurements give the "fingerprint" of the sample but do not characterise all created centres.

The analysis of photoconductivity spectrum dependence on temperature shows that an additional photoconductivity band appears at higher temperatures. For analysis of this phenomenon, the thermally stimulated conductivity was inves-

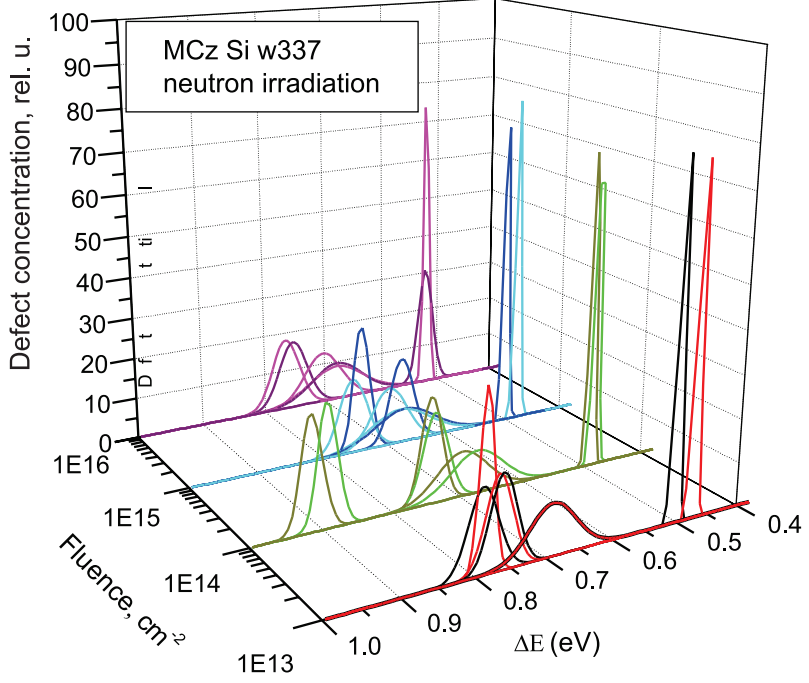

Fig. 4. The dependence of the relative contribution of the deep level if its activation energy is approximated by the Gaussian distribution on the fluence.

tigated and it was found that an additional photoconductivity band appeared if the traps were emptied. This can be explained by the model that at low temperature all traps are filled by non-equilibrium carriers and the photoionisation spectra show the contribution of all deep levels. If temperature is high enough to empty the shallow level, then the electron can be excited by the light to this centre (and the free hole is generated, too) and the thermal energy excites this electron to the conduction band. Figure 5(a) shows the details of the photoconductivity spectra measured at different temperatures, and thermally stimulated current dependences on temperature are presented in Fig. 5(b), which shows what levels are emptied at the correspondent temperature. The spectral shift corresponds to the level below the conduction band at approximately $75 \pm 3 \mathrm{meV}$ (optical activation energy), and it corresponds to the level determined by the thermally stimulated current method with the thermal activation energy of $70 \mathrm{meV}$. The increase of temperature enhances the thermal excitation rate; therefore, the new band intensity increases with temperature. The photoconductivity dependence on temperature presented in Fig. 5(b) (the data marked "PC") demonstrates that free carrier mobility and lifetime weakly depend on temperature or these dependencies compensate each other, which needs further analysis. 

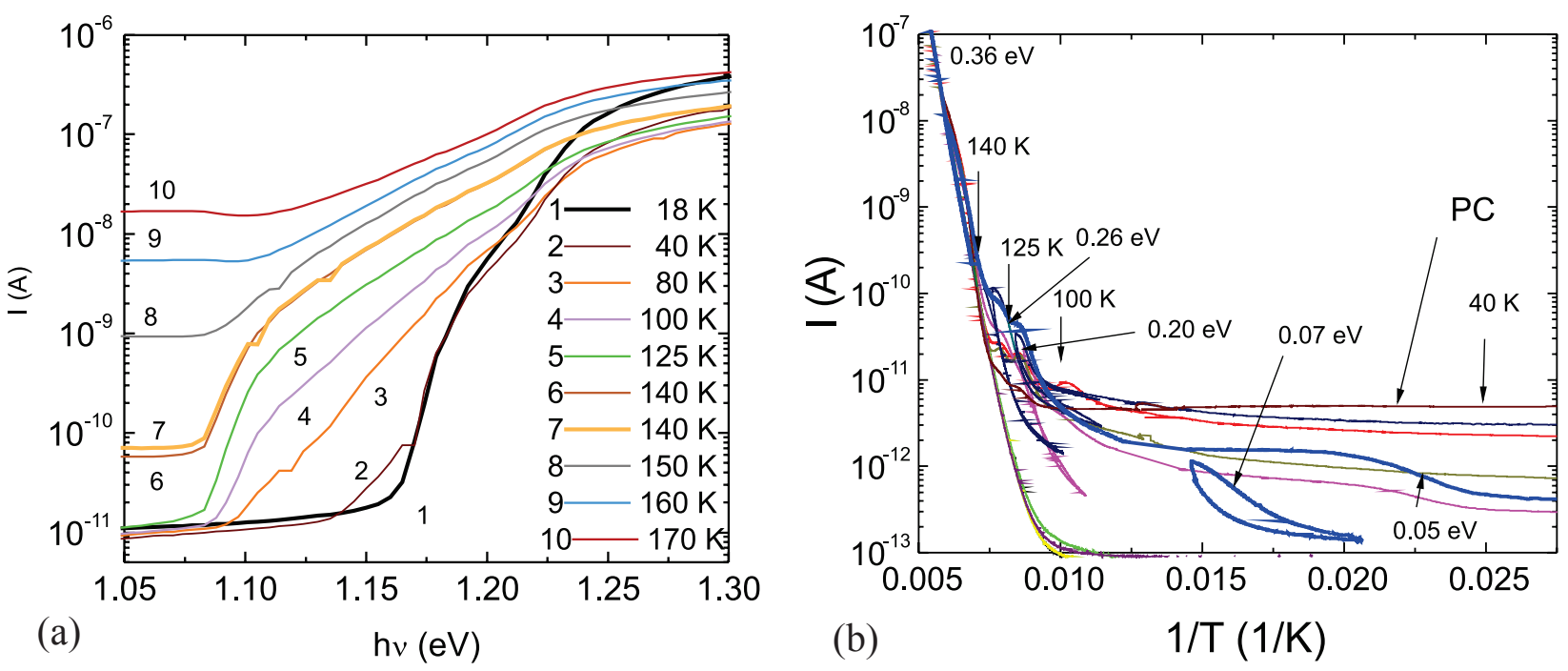

Fig. 5. (a) Photoconductivity spectral dependence at different temperature in the irradiated Si (neutron fluence $10^{13} \mathrm{~cm}^{-2}$ ). (b) Thermally stimulated current in the same sample measured by multiple heating regime. The trap activation energies are shown on the graph. The label PC shows the temperature dependence of photoconductivity.

\section{Conclusions}

Photoconductivity transient behaviour permitted to recognize the main recombination centre property: the change of the recombination cross-section with the fluence dependent compensation of Si. PC spectra allow to reveal the main groups of defects and their changes with fluence and annealing. The two-step (optical and thermal) intrinsic generation of carriers was demonstrated in the irradiated $\mathrm{Si}$.

\section{Acknowledgements}

This work was performed as a part of CERN RD50 collaboration and was supported by the Lithuanian Science Council grant No. MIP-068/2011.

\section{References}

[1] K. Wehe, Current trends in ionising radiation detectors, Nuclear Engineering and Technology 38(4), 311-318 (2006).

[2] M. Moll, J. Adey, A. Al-Ajili, et al. Development of radiation tolerant semiconductor detectors for Super-LHC, Nucl. Instr.um and Methods. A 546, 99-107 (2005).

[3] M. Huhtinen, Simulation of non-ionising energy loss and defect formation in silicon, Nucl. Instrum. Methods. A 491, 194-215 (2002).
[4] G. Davies, S. Hayama, L. Murin, R. KrauseRehberg, V. Bondarenko, A. Sengupta, C. Davia, and A. Karpenko, Radiation damage in silicon exposed to high-energy protons, Phys. Rev. B 73(16), 165-202 (2006).

[5] L.I. Murin, J.L. Lindström, G. Davies, and V.P. Markevich, Evolution of radiation-induced carbon-oxygen-related defects in silicon upon annealing: LVM studies, Nucl. Instrum. Methods. B 253, 210-213 (2006).

[6] E. Fretwurst, F. Hönniger, G. Kramberger, G. Lindström, I. Pintilie, and R. Röder, Radiation damage studies on $\mathrm{MCz}$ and standard and oxygen enriched epitaxial silicon devices,Nucl. Instrum. Methods. Res. A 583, 58-63 (2007).

[7] E. Gaubas, T. Čeponis, A. Uleckas, and J. Vaitkus, Anneal dependent variations of recombination and generation lifetime in neutron irradiated $\mathrm{MCZ}$ Si, Nucl. Instrum. Methods. A 612(3), 563-565 (2010).

[8] D. Menichelli on behalf of the RD50 collaboration. Recent developments of the CERN RD50 collaboration, Nucl. Instrum. Methods. 596, 48-52 (2008).

[9] V. Kažukauskas, J. Storasta, and J.V. Vaitkus, Interaction of deep levels and potential fluctuations in scattering and recombination phenomena in semi-insulating GaAs, J. Appl. Phys. 80(4), 2269-2278 (1996).

[10]J. Vaitkus and J. Viščakas. On the determination of parameters of defect levels, Lith. J. Phys. 6(1), 59-65 (1966), [in Russian]. 
[11]G. Lucovsky, On the photoionization of deep impurity centers in semiconductors, Solid State Commun. 3(9), 299-302 (1965).

[12]J.L. Hastings, S.K. Estreicher, and P.A. Fedders, Vacancy aggregates in silicon, Phys. Rev. B 56, 10215-10220 (1997).
[13] V. Kalendra, E. Gaubas, V. Kazukauskas, E. Zasinas, and J.Vaitkus, Photoconductivity spectra and deep levels in the irradiated $\mathrm{p}^{+}-\mathrm{n}-\mathrm{n}^{+}$Si detectors, Nucl. Instrum. Methods. A 612, 555-558 (2010).

\title{
GILIUUJU CENTRU ITAKA KRŪVININKU GENERACIJAI IR REKOMBINACIJAI NEUTRONAIS APŠVITINTAME DIDELĖS SPECIFINĖS VARŽOS SILICYJE
}

\author{
J. Vaitkus, R. Bondzinskas, V. Kažukauskas, P. Malinovskis, A. Mekys, G. Mockevičius, J. Storasta, \\ N. Vainorius, E. Žąsinas
}

Vilniaus universiteto Taikomuju mokslu institutas ir Puslaidininkiu fizikos katedra, Vilnius, Lietuva

\section{Santrauka}

Priemaišiniu fotolaidumo spektru metodu ištirti gilieji centrai neutronais apšvitintuose $\mathrm{FZ}$ ir $\mathrm{MCz} \mathrm{Si}$. Tyrimai atlikti esant $18-120 \mathrm{~K}$ temperatūrai. Duomenys analizuoti panaudojant Lukovskio modeli, aproksimuojant centrų energijų pasiskirstymą draustinėje juostoje Gauso funkcija, bei pasiektas geras eksperimento ir modeliavimo rezultatų atitikimas. Nustatyta, kad giliụjų centrų koncentracijos kinta nemonotoniškai ban- dinius atkaitinant bei priklauso nuo apšvitos dydžio. Fotolaidumo relaksacija buvo ištirta foto-Holo efekto metodu ir nustatyti pagrindinio rekombinacijos centro parametrai; jo modelis yra pasiūlytas. Fotolaidumo spektrų ir termostimuliuotų srovių tyrimas parodé, kad nepusiausvyrūs krūvininkai gali būti sužadinami pakopiniu mechanizmu, optiniu būdu ị lokalinị lygmenị ir termiškai iš to lygmens ị zoną. 